\title{
Modeling and Distribution Laws of Drilling Force for Staggered Teeth BTA Deep Hole Drill
}

\author{
Xubo Li, Jianming Zheng $\mathbb{D}^{\mathbb{D}}$, Yan Li $\mathbb{D}^{D}$, Lingfei Kong $\mathbb{D}^{D}$, Weichao Shi, and Bian Guo \\ School of Mechanical and Precision Instrument Engineering, Xian University of Technology, Xi'an 710048, China \\ Correspondence should be addressed to Jianming Zheng; zjm@xaut.edu.cn
}

Received 27 July 2018; Accepted 27 September 2018; Published 9 October 2018

Academic Editor: Eric Feulvarch

Copyright (C) 2018 Xubo Li et al. This is an open access article distributed under the Creative Commons Attribution License, which permits unrestricted use, distribution, and reproduction in any medium, provided the original work is properly cited.

\begin{abstract}
The boring and trepanning association (BTA) deep hole drilling is a typical self-guiding machining method. The drilling force and its distribution laws along the cutting radius directly affect the stability of drilling and the quality of machined hole. Based on the oblique cutting theory, a novel drilling force model is developed to predict the thrust and torque for staggered teeth BTA deep hole drill with variable geometries. Using the constraint relationships between the cutting force components and cutting angles, combined with the measured drilling force during the drill entrance, the parameters of the model including normal shear angle, normal friction angle and shear stress involved in the cutting force coefficients along the cutting radius, and the axial and circumferential friction coefficients between the guide pads and the hole wall are obtained. The model-predicted drilling force is validated by experimental results.
\end{abstract}

\section{Introduction}

The BTA deep hole drilling is commonly used in high precision and high length-to-diameter ratio deep hole machining in the field of new energy, aerospace, and military industries $[1,2]$. The staggered teeth BTA drill adopts multiple teeth cutting, and two guide pads are also distributed on the outside of the drill to balance the cutting force of the tooth and to perform self-guiding of the drilling. The drilling force and its distribution laws with the cutting radius directly affect the stability of drilling and the quality of machined hole [3-5]. In addition, drilling force is an important physical quantity for selecting the drilling process parameters and monitoring the drilling state as well as causing drill wear [6], tool system deformation [7], and chatter [8]. Therefore, it is of great significance to establish an accurate model to predict the drilling force of staggered teeth BTA deep hole drilling.

Jung et al. [9] and Sahu et al. [10] presented a functional relationship for gundrilling between the cutting force coefficients and uncut layer thickness, effective rake angle, and cutting speed. The empirical model of the drilling force was obtained by experiments. Woon et al. [11] proposed a cutting force model of tooth for gundrilling, under the simultaneous consideration of cutting and plowing, and the cutting force coefficients along cutting edge were regarded as constants. Biermann et al. [12] used BTA deep hole drilling experiments on a large number of different diameter workpieces, indicating that the drilling force along the drilling radius was nonuniform. Lazar et al. [13] and Watson et al. [14] revealed that the cutting force coefficients along the cutting radius of the twist drill were nonlinear with the cutting radius. The smaller the cutting radius is, the greater the cutting force coefficients are.

Gao et al. [15] exposed that the chip thickness deformation coefficients and the drilling force for staggered teeth BTA deep hole drilling are consistent with the cutting radius. Astakhov et al. [16, 17] used the constraint relationship between the chip thickness deformation coefficients and the shear angle to establish a drilling force model with the cutting radius distribution. However, Ke et al. [18] presented that the chip discharging process in deep hole drilling is affected by the chip removal channel, and the chip at the large diameter edge of the tooth will have a thickening effect. Therefore, the chip thickness of deep hole drilling is not the original chip thickness in the cutting area formed, and the chip thickness deformation coefficient is not the actual value, so it was 


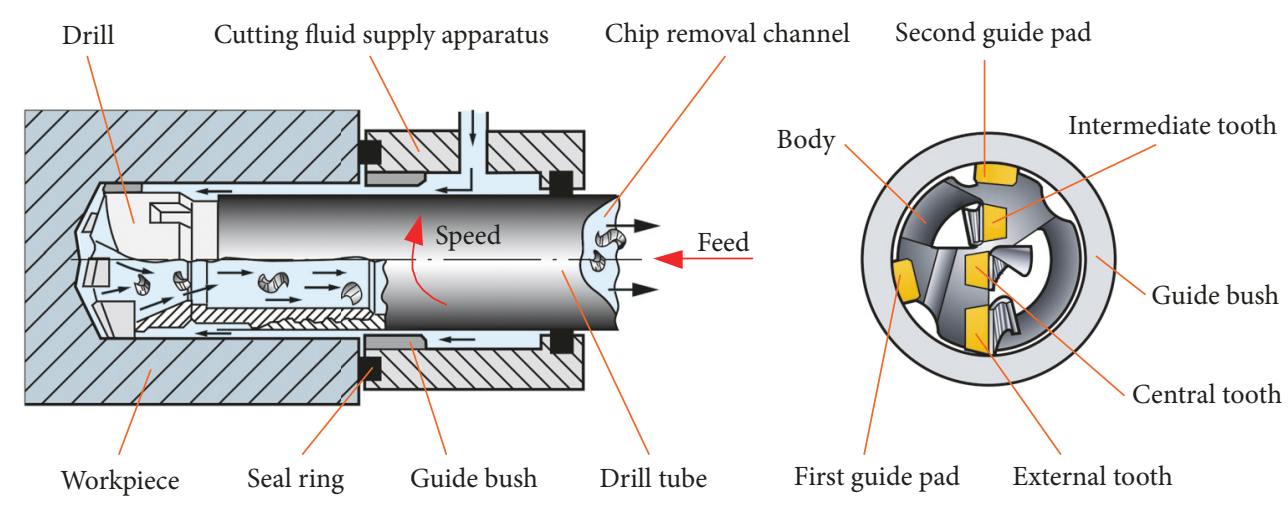

FIGURE 1: Working schematic of BTA deep hole machining system.

unable to calculate the shear angle with the distribution of the cutting radius.

It is also worth noting that the guide pad is used not only to balance the cutting force of the teeth to ensure self-guiding of the drilling, but also to improve the surface quality of the hole wall by its plastic extrusion contact with the hole wall [19-21]. The normal force on the guide pads directly affects the depth of the extrusion deformation layer on the hole wall, thus affecting the drilled hole diameter, roundness, and surface roughness [22].

In order to improve the stability of the drilling and the quality of the machined hole, the appropriate width and angles for the teeth and guide pads should be selected; therefore, the distribution laws of the cutting force with the cutting radius need to be clarified. In this paper, a new method of modeling the drilling force of the staggered teeth BTA deep hole drill with variable geometries is proposed based on the oblique cutting theory. The relevant parameters in the model are identified using the drilling force during the drill entrance, and the distribution laws of the cutting force coefficients along the cutting radius are analyzed. The validity of the proposed approach is verified by experimental results. This study will lay a fundamental for optimizing the drill structure and the drilling process parameters.

\section{Drilling Force Model}

2.1. Drilling Force Analysis. The schematic of the BTA deep hole drilling system is shown in Figure 1. During drilling, the cutting oil is injected from the cutting fluid supply apparatus to the cutting zone through the annular gap between the hole wall and the drill tube, which cools and lubricates the cutting edge and pushes the formed chip by the teeth into the chip removal channel of the drill in the opposite direction and then is evacuated to the chip accumulation box. After chip separation, the cutting oil is recycled through the oil pump to ensure continuous drilling.

BTA deep hole drilling is a compound machining of rough cutting of the teeth in the workpiece and semifinishing burnishing of the guide pads on the hole wall. The staggered teeth BTA drill contains three teeth of asymmetrical dislocation, and two guide pads are distributed on the circumference outside of the drill. The guide pad plays a supporting and guiding role for the drill, which burnishes the contact with the hole wall, balances the cutting force of the teeth, realizes self-guiding in drilling, and improves the quality of the drilled hole.

The force analysis of staggered BTA deep hole drilling is shown in Figure 2. As the cutting resultant force of the teeth is located in between two guide pads, the force on the peripheral land face of the external tooth is so small that it can be ignored in the modeling [11]. Elastoplastic burnishing friction between the guide pads and the hole wall can be equivalent to the sliding friction [18]. Therefore, the drilling force can be given as follows:

$$
\begin{gathered}
F_{\mathrm{Z}}=F_{\mathrm{ZC}}+F_{\mathrm{ZB}} \\
M_{\mathrm{Z}}=M_{\mathrm{ZC}}+M_{\mathrm{ZB}}
\end{gathered}
$$

where $F_{\mathrm{ZC}}$ is the total thrust from teeth cutting, $M_{\mathrm{ZC}}$ is the total torque from teeth cutting, $F_{Z B}$ is the total thrust from burnishing friction of guide pads, and $M_{Z B}$ is the total torque from burnishing friction of guide pads.

2.2. Cutting Force of the Tooth. According to the structure and cutting conditions of the staggered teeth BTA drill, the tooth cutting can be equivalent to oblique cutting [23]. The cutting edge of the tooth is segmented into small discrete elements along the cutting radius, as shown in Figure 3. The cutting force of the cutting edge microelement is given as

$$
\begin{aligned}
& d F_{\mathrm{T}, i}=K_{\mathrm{T}, i} t_{\mathrm{c} 0, i} d w_{i} \\
& d F_{\mathrm{R}, i}=K_{\mathrm{R}, i} t_{\mathrm{c} 0, i} d w_{i} \\
& d F_{\mathrm{A}, i}=K_{\mathrm{A}, i} t_{\mathrm{c} 0, i} d w_{i}
\end{aligned}
$$

where $d F_{\mathrm{T}, i}, d F_{\mathrm{R}, i}$, and $d F_{\mathrm{A}, i}$ are the tangential force, radial force, and axial force of the cutting edge microelement, respectively ( $i$ is the code for the teeth, and 1, 2, and 3, resp., represent central tooth, intermediate tooth, and external tooth). $K_{\mathrm{T}, i}, K_{\mathrm{R}, i}$, and $K_{\mathrm{A}, i}$ are tangential, radial and axial cutting force coefficients, respectively. The correction cutting 

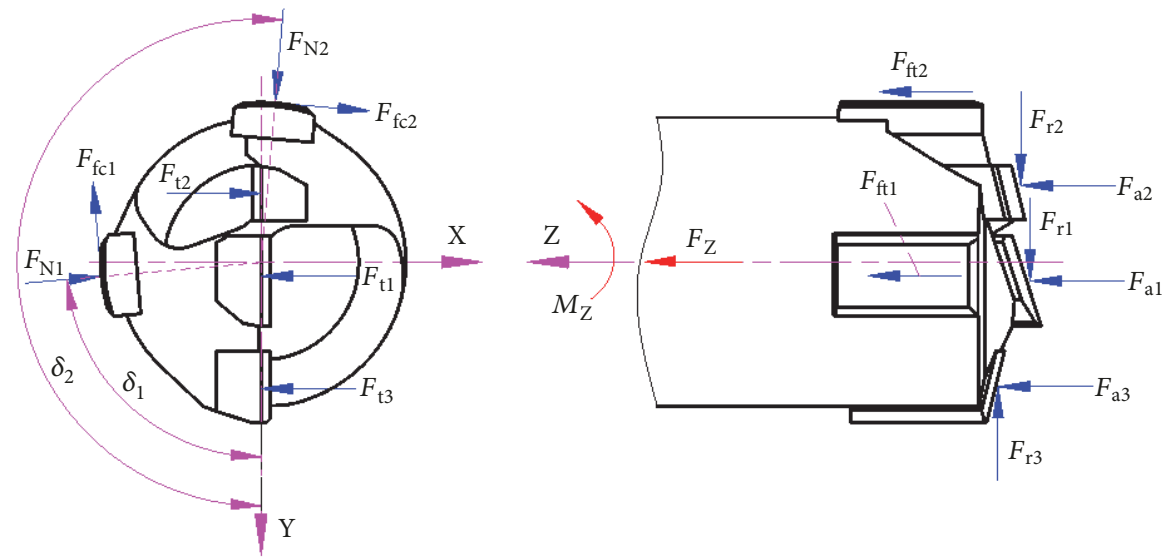

FIgURE 2: The system of forces acting in staggered teeth BTA drilling.

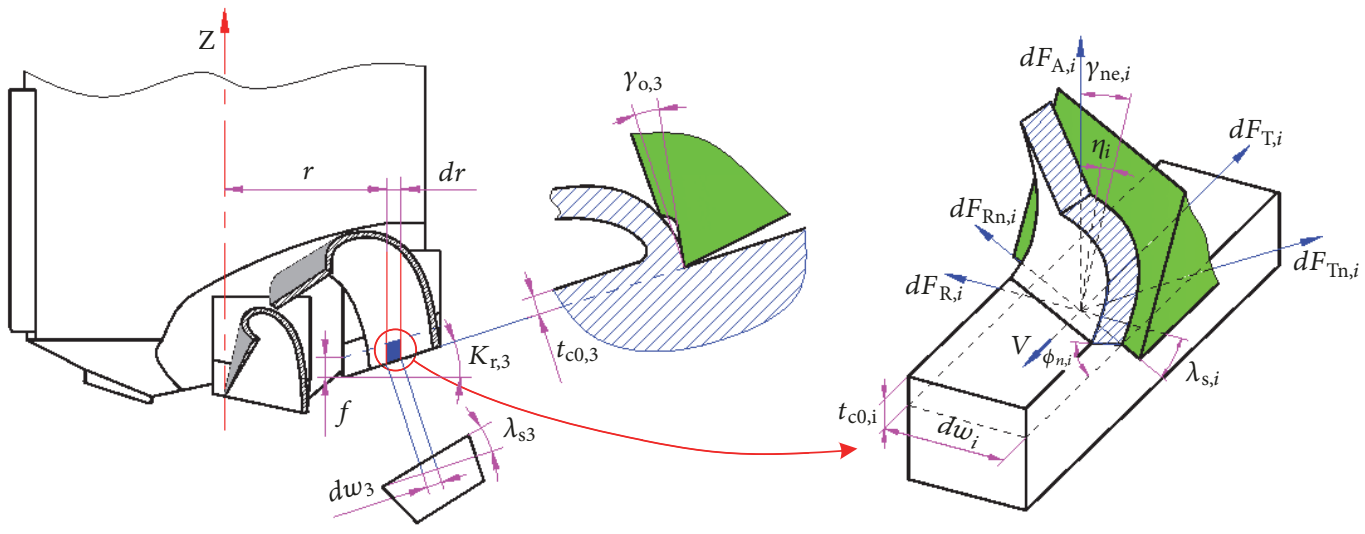

FIgURE 3: Microelement cutting force of the tooth.

force coefficients based on the oblique model proposed by Armarego et al. [24] can be derived as

$$
\begin{array}{r}
K_{\mathrm{T}, i}=\frac{\tau_{\mathrm{s}}}{\sin \phi_{\mathrm{n}, i}} \\
\cdot \frac{\cos \left(\beta_{\mathrm{n}, i}-\gamma_{\mathrm{ne} . i}\right)+\tan \lambda_{\mathrm{s}, i} \tan \eta_{i} \sin \beta_{\mathrm{n}, i}}{\sqrt{\cos ^{2}\left(\phi_{\mathrm{n}, i}+\beta_{\mathrm{n}, i}-\gamma_{\mathrm{ne}, i}\right)+\tan ^{2} \eta_{i} \sin ^{2} \beta_{\mathrm{n}, i}}} \\
K_{\mathrm{R}, i}=\frac{\tau_{\mathrm{s}}}{\sin \phi_{\mathrm{n}, i}} \\
\cdot \frac{\cos \left(\beta_{\mathrm{n}, i}-\gamma_{\mathrm{ne}, i}\right) \tan \lambda_{\mathrm{s}, i}-\tan \eta_{i} \sin \beta_{\mathrm{n}, i}}{\sqrt{\cos ^{2}\left(\phi_{\mathrm{n}, i}+\beta_{\mathrm{n}, i}-\gamma_{\mathrm{ne}}\right)+\tan ^{2} \eta_{i} \sin ^{2} \beta_{\mathrm{n}, i}}} \\
K_{\mathrm{A}, i}=\frac{\tau_{\mathrm{s}}}{\sin \phi_{\mathrm{n}, i} \cos \lambda_{\mathrm{s}, i}} \\
\cdot \frac{\sin \left(\beta_{\mathrm{n}, i}-\gamma_{\mathrm{ne}, i}\right)}{\sqrt{\cos ^{2}\left(\phi_{\mathrm{n}, i}+\beta_{\mathrm{n}, i}-\gamma_{\mathrm{ne}, i}\right)+\tan ^{2} \eta_{i} \sin ^{2} \beta_{\mathrm{n}, i}}}
\end{array}
$$

where $\beta_{\mathrm{n}, i}$ is normal friction angle, $\phi_{\mathrm{n}, i}$ is normal shear angle, $\tau_{\mathrm{s}}$ is shear flow stress on the shear plane, $\lambda_{\mathrm{s}, i}$ is edge inclination angle, $\eta_{i}$ is chip flow angle, and $\gamma_{\text {ne }, i}$ is normal working rake angle.

Considering the geometric conditions, the uncut layer thickness is given as

$$
t_{\mathrm{c} 0, i}=f \cos K_{\mathrm{r}, i}
$$

The corresponding cutting width is

$$
d w_{i}=\frac{d r}{\cos K_{\mathrm{r}, i}}
$$

where $f$ is feed per rotation and $K_{r, i}$ is approach angle.

The tangential, radial, and axial forces of cutting edge microelement from (3) can be transformed into the tooth coordinate system using approach angle $K_{\mathrm{r}, i}$ :

$$
\begin{aligned}
& {\left[\begin{array}{lll}
d F_{\mathrm{t}, i} & d F_{\mathrm{r}, i} & d F_{\mathrm{a}, i}
\end{array}\right]^{\mathrm{T}}=\mathbf{T}\left(K_{\mathrm{r}, i}\right)\left[\begin{array}{lll}
d F_{\mathrm{T}, i} & d F_{\mathrm{R}, i} & d F_{\mathrm{A}, i}
\end{array}\right]^{\mathrm{T}}} \\
& \mathbf{T}\left(K_{\mathrm{r}, i}\right)=\left[\begin{array}{ccc}
1 & 0 & 0 \\
0 & \cos K_{\mathrm{r}, i} & \sin K_{\mathrm{r}, i} \\
0 & -\sin K_{\mathrm{r}, i} & \cos K_{\mathrm{r}, i}
\end{array}\right]
\end{aligned}
$$


Therefore, the thrust and torque of the teeth cutting can be predicted as

$$
\begin{aligned}
F_{\mathrm{ZC}} & =\sum_{i=1}^{i=n} \int_{r_{i}}^{R_{i}} d F_{a, i} \\
M_{\mathrm{ZC}} & =\sum_{i=1}^{i=n} \int_{r_{i}}^{R_{i}} r d F_{\mathrm{t}, i}
\end{aligned}
$$

where $R_{i}$ is maximum radius of the tooth, $r_{i}$ is minimum radius of the tooth, and $n$ is the number of teeth.

2.3. Burnishing Friction Force of the Guide Pad. The resultant force of the teeth cutting in the $\mathrm{X}$ direction is

$$
F_{\mathrm{CX}}=-\int_{r_{1}}^{R_{1}} d F_{\mathrm{t}, i}+\int_{r_{2}}^{R_{2}} d F_{\mathrm{t}, i}-\int_{r_{3}}^{R_{3}} d F_{\mathrm{t}, i}
$$

The resultant force of the teeth cutting in the $\mathrm{Y}$ direction is

$$
F_{\mathrm{CY}}=\int_{r_{1}}^{R_{1}} d F_{\mathrm{r}, i}+\int_{r_{2}}^{R_{2}} d F_{\mathrm{r}, i}-\int_{r_{3}}^{R_{3}} d F_{\mathrm{r}, i}
$$

According to the zero resultant forces in the $\mathrm{X}$ and $\mathrm{Y}$ directions of the drill, that is, $\sum F_{\mathrm{X}}=0$ and $\sum F_{\mathrm{Y}}=0$, the normal forces acting on the each guide pad can be obtained as follows:

$$
\begin{aligned}
& F_{\mathrm{N} 1} \\
& =\frac{F_{\mathrm{CX}}\left(\cos \delta_{2}+\mu_{\mathrm{c}} \sin \delta_{2}\right)+F_{\mathrm{CY}}\left(\sin \delta_{2}-\mu_{\mathrm{c}} \cos \delta_{2}\right)}{\left(\mu_{\mathrm{c}}^{2}+1\right) \sin \left(\delta_{2}-\delta_{1}\right)} \\
& F_{\mathrm{N} 2} \\
& =\frac{F_{\mathrm{CX}}\left(\cos \delta_{1}+\mu_{\mathrm{c}} \sin \delta_{1}\right)+F_{\mathrm{CY}}\left(\sin \delta_{1}-\mu_{\mathrm{c}} \cos \delta_{1}\right)}{\left(\mu_{\mathrm{c}}^{2}+1\right) \sin \left(\delta_{1}-\delta_{2}\right)}
\end{aligned}
$$

where $\delta_{1}$ is the position angle of the first guide pad and $\delta_{2}$ is the position angle of the second guide pad.

Hence, the thrust and torque sourced from the burnishing friction of guide pads can be given as

$$
\begin{aligned}
F_{\mathrm{ZB}} & =F_{\mathrm{fa} 1}+F_{\mathrm{fa} 2}=\mu_{\mathrm{t}}\left(F_{\mathrm{N} 1}+F_{\mathrm{N} 2}\right) \\
M_{\mathrm{ZB}} & =R F_{\mathrm{fc} 1}+R F_{\mathrm{fc} 2}=\mu_{\mathrm{c}} R\left(F_{\mathrm{N} 1}+F_{\mathrm{N} 2}\right)
\end{aligned}
$$

where $\mu_{\mathrm{t}}$ and $\mu_{\mathrm{c}}$ are axial and circumferential friction coefficients between the guide pads and the hole wall, respectively. $R$ is the drill radius.

Finally, the total thrust and torque of the staggered teeth BTA deep hole drilling are predicted by substituting (9) and (15) into (1) and (10) and (16) into (2), which can then be expressed as follows:

$$
\begin{aligned}
F_{\mathrm{Z}} & =\sum_{i=1}^{i=n} \int_{r_{i}}^{R_{i}} d F_{\mathrm{a}, i}+\frac{\mu_{t}\left(\left(F_{\mathrm{CX}}-\mu_{c} F_{\mathrm{CY}}\right)\left(\cos \delta_{2}-\cos \delta_{1}\right)+\left(\mu_{c} F_{\mathrm{CX}}+F_{\mathrm{CY}}\right)\left(\sin \delta_{2}-\sin \delta_{1}\right)\right)}{\left(1+\mu_{c}^{2}\right) \sin \left(\delta_{2}-\delta_{1}\right)} \\
M_{\mathrm{Z}} & =\sum_{i=1}^{i=n} \int_{r_{i}}^{R_{i}} r d F_{\mathrm{t}, i}+\frac{\mu_{c} R\left(\left(F_{\mathrm{CX}}-\mu_{c} F_{\mathrm{CY}}\right)\left(\cos \delta_{2}-\cos \delta_{1}\right)+\left(\mu_{c} F_{\mathrm{CX}}+F_{\mathrm{CY}}\right)\left(\sin \delta_{2}-\sin \delta_{1}\right)\right)}{\left(1+\mu_{c}^{2}\right) \sin \left(\delta_{2}-\delta_{1}\right)}
\end{aligned}
$$

\section{Identification of Model Parameters}

The unknown parameters in the BTA drilling force model include $\beta_{\mathrm{n}, i}, \phi_{\mathrm{n}, i}, \tau_{\mathrm{s}}, \eta_{i}$, and $\gamma_{\mathrm{ne}, i}$ in the cutting force coefficients of the teeth and $\mu_{\mathrm{t}}$ and $\mu_{\mathrm{c}}$ in the friction coefficients of guide pads.

3.1. Distribution Force Extraction. The measured thrust and torque of the staggered teeth BTA deep hole drilling during the drill entrancing are shown in Figure 4. The schematic diagram of the teeth cutting and guide pads burnishing into the workpiece at the drill entrance is shown in Figure 5. At the beginning, the maximum radius of the central tooth is cut into and forms a centering ring. Then, the minimum radius of the intermediate tooth is plunged into so that the radial force generated by the central tooth cutting is balanced, and the cutting of the two teeth has continuity. Next, the external tooth is accessed into successively; for better chip separation, there is a lag between the cutting edge of the external tooth and the max radius of intermediate tooth. Finally, the guide pads are burnished into. To ensure that the burnishing of the guide pad occurs after the tooth cutting, there is also a setback of a certain distance between the guide pads and the max radius of the external tooth. According to the drill structural characteristics, the drilling force during the drill entrance can be divided into three stages; namely, I stage is the central and intermediate teeth cutting, II stage is the external tooth cutting, and III stage is the guide pads burnishing.

At the entrance stage of the teeth, the cutting force increases as the cutting radius of the tooth increases. It is worth noting that, at this stage, the guide pad remains in the guide bush. At the entrance stage of the guide pads stage, the drilling force increases rapidly and then decreases to a stable magnitude. Since the guide bush and drill are in a clearance fit, the guide bush diameter $D_{\mathrm{B}}$ is larger than the drill diameter $D_{\mathrm{T}}$, and the guide pads are against the guide bush while the teeth are cutting [20]. Thus, the formed cutting hole diameter $D_{\mathrm{c}}$ is smaller than $D_{\mathrm{T}}$, as shown in Figure 5(a). It will lead to a sudden increase of the drilling force when the guide pads are burnishing into the cut hole. Therefore, the variation of drilling force before entering of the guide 


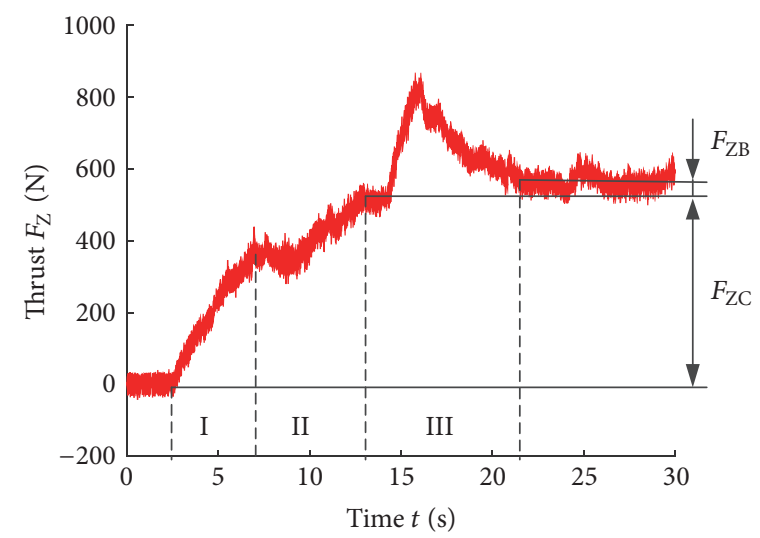

(a) Thrust

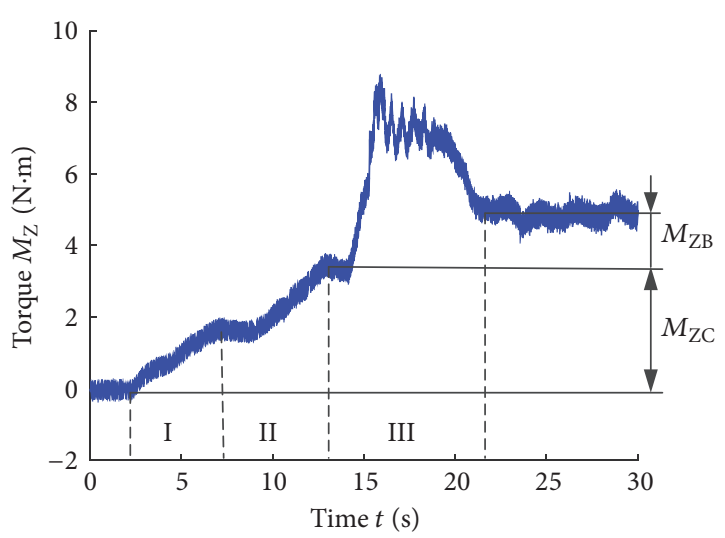

(b) Torque

FIgURE 4: The thrust and torque during the drill entrance (I, central and intermediate tooth cutting, II, external tooth cutting, and III, guide pads burnishing).

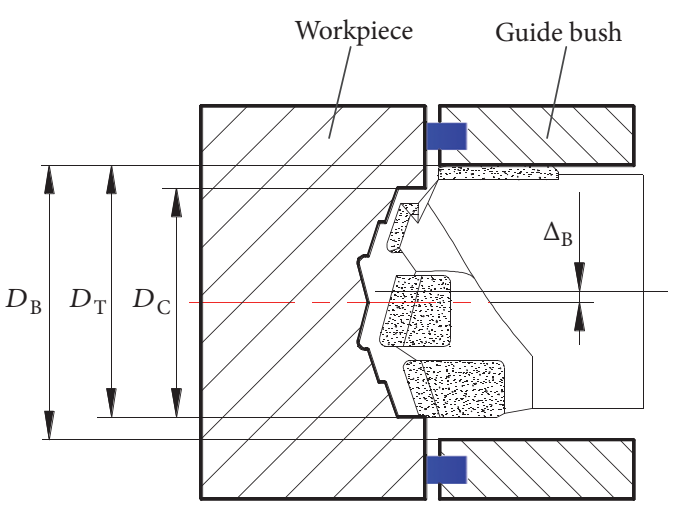

(a) Teeth cutting

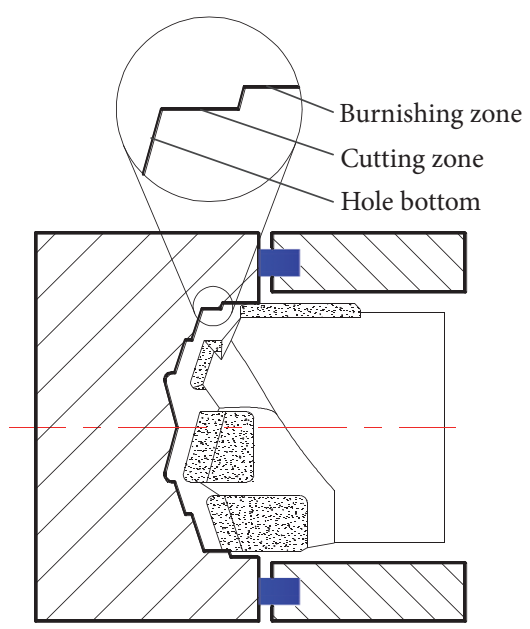

(b) Guide pads burnishing

FIGURE 5: Schematic diagram of BTA deep hole drilling process.

pads is thrust $F_{\mathrm{ZC}}$ and torque $M_{\mathrm{ZC}}$ from the teeth cutting; the increment of drilling force after entering is thrust $F_{\mathrm{ZB}}$ and torque $M_{\mathrm{ZB}}$ from the guide pads burnishing.

It is noted that the extracted thrust $F_{\mathrm{ZC}}$ and torque $M_{\mathrm{ZC}}$ are functions of drilling time $t$, the corresponding relationship between drilling depth and cutting radius is as shown in Figure 6, and the $\mathrm{z}$ direction is opposite to the drilling feed direction. Thus, the cutting radius can be related to the drilling depth and drilling time by the following equation:

$$
d r=\frac{d z}{\tan K_{\mathrm{r}, i}}=\frac{n \cdot f \cdot d t}{\tan K_{\mathrm{r}, i}}
$$

where $d z$ is the drilling depth per unit time and $n$ is rotating speed.

If the sampling frequency of the drilling force is fs, the number of data points of drilling force collected during the teeth cutting stage (corresponding drilling depth $0 \sim z_{5}$ ) is $N$ $\left(N=\left(z_{5} \cdot \mathrm{fs}\right) /(n \cdot f)\right)$. The drilling force during the teeth cutting stage can be divided into $U$ units and $m$ samples

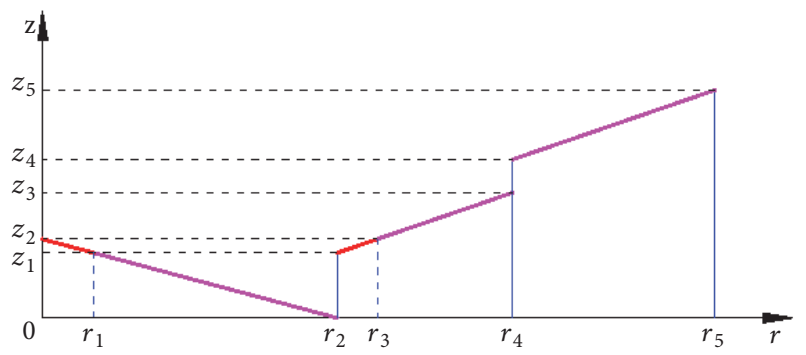

FIGURE 6: The relationship between drilling depth and cutting radius.

as a unit. Therefore, the drilling force of each unit can be calculated as

$$
\begin{aligned}
F_{\mathrm{ZC}}(u) & =\frac{1}{m} \sum_{j=(u-1) m}^{u m} F_{\mathrm{ZC}}(j) \\
M_{\mathrm{ZC}}(u) & =\frac{1}{m} \sum_{j=(u-1) m}^{u m} M_{\mathrm{ZC}}(j)
\end{aligned}
$$

in which $j=1,2, \ldots, N$ and $u=1,2, \ldots, U$. 


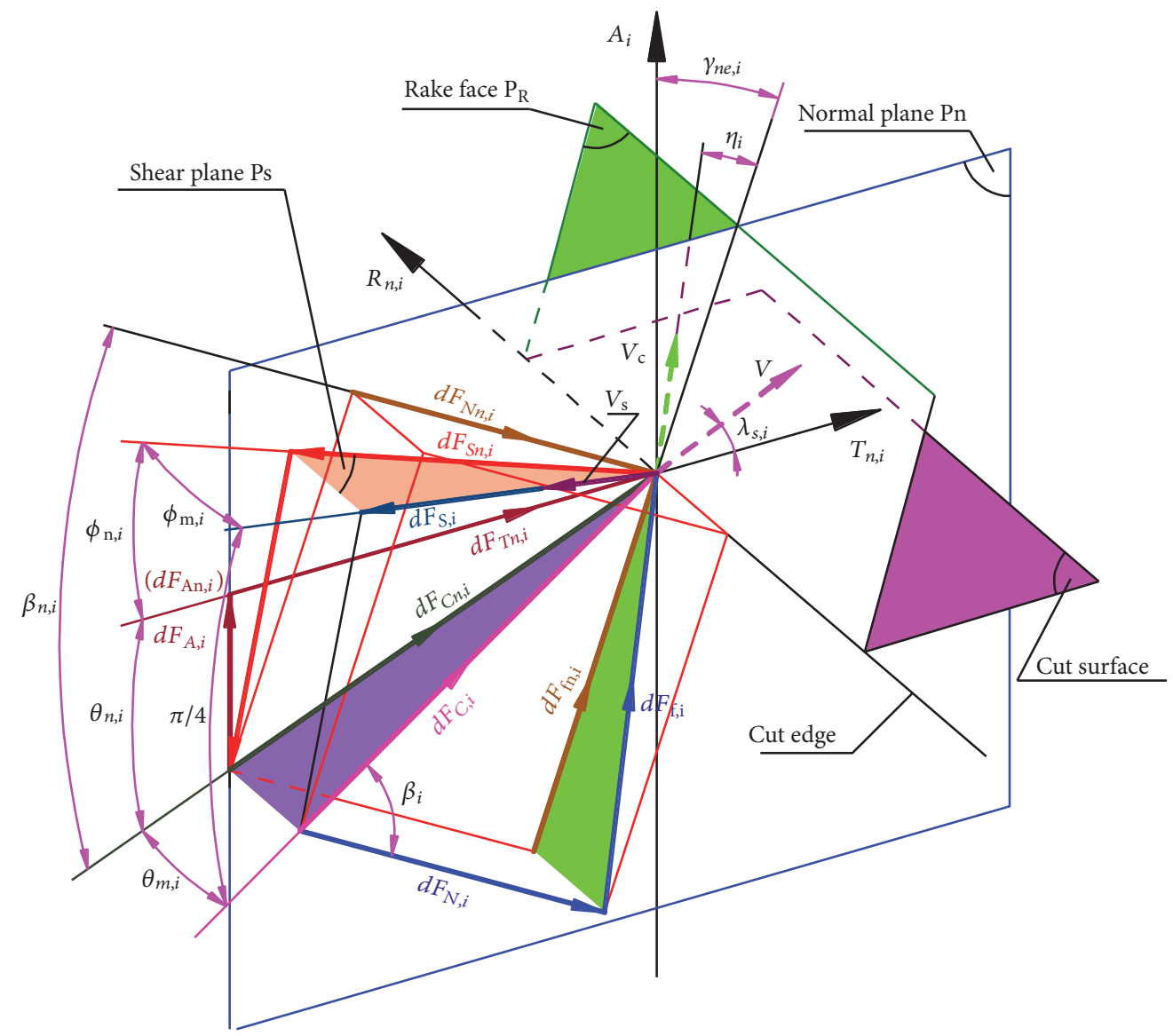

FIGURE 7: Relationship between cutting force components and cutting angle.

The number of the overlapped range $z_{1} \sim z_{2}$ units for the central and intermediate tooth is $W$. The unit cutting force of the intermediate tooth cutting radius range $r_{2} \sim r_{3}$ is obtained by spline curve interpolation of the cutting radius range $r_{3} \sim r_{4}$; the unit cutting force of the central tooth radius range $r_{1} \sim 0$ is obtained by the overlapped range to subtract the intermediate tooth cutting radius range $r_{2} \sim r_{3}$ and elimination of $P$ units of the drilling depth range $z_{3} \sim z_{4}$. Thus, the thrust and torque corresponding to $Q(Q=U+W-P)$ units cutting radius $d r$ of the teeth are obtained. According to [3], the tooth cutting radial force is 0.5 times the axial force in BTA deep hole drilling, so $d F_{\mathrm{r}, i}=0.5 d F_{\mathrm{a}, i}$. Therefore, three force components $\left(d F_{\mathrm{t}, i}, d F_{\mathrm{r}, i}\right.$, and $\left.d F_{\mathrm{a}, i}\right)$ corresponding to the cutting radius unit $d r$ of teeth can be acquired.

\subsection{Constraint between Cutting Parameters. The relationship} between cutting force components and cutting angles on the cutting edge microelement is shown in Figure 7 , in which $d F_{\mathrm{C}, i}$ is the total cutting force and $d F_{\mathrm{S}, i}$ is shear force. $d F_{\mathrm{N}, i}$ is normal force acting on the rake face. $d F_{\mathrm{f}, i}$ is friction force acting on the rake face. $d F_{\mathrm{Tn}, i}, d F_{\mathrm{Rn}, i}$, and $d F_{\mathrm{Cn}, i}$ are projections of $d F_{\mathrm{T}, i}, d F_{\mathrm{R}, i}$, and $d F_{\mathrm{A}, i}$ at the normal plane Pn, respectively. $\phi_{\mathrm{m}, i}$ is the angle between $d F_{\mathrm{S}, i}$ and normal plane Pn. $\theta_{\mathrm{m}, i}$ is the angle between $d F_{\mathrm{C}, i}$ and normal plane Pn. $\theta_{\mathrm{n}, i}$ is the angle between $d F_{\mathrm{Cn}, i}$ and $d F_{\mathrm{Tn}, i} \cdot \beta_{i}$ is friction angle.
The cutting force components and cutting angles satisfy the following equations:

$$
\begin{aligned}
& d F_{\mathrm{f}, i}=d F_{\mathrm{N}, i} \tan \beta_{i}=d F_{\mathrm{N}, i} \frac{\tan \beta_{\mathrm{n}, i}}{\cos \eta_{i}} \\
& d F_{\mathrm{f}, i}=d F_{\mathrm{C}, i} \sin \beta_{i}=d F_{\mathrm{C}, i} \frac{\sin \theta_{\mathrm{m}, \mathrm{i}}}{\sin \eta_{i}}
\end{aligned}
$$

Derived by (22) and (23),

$$
\begin{aligned}
& \tan \beta_{\mathrm{n}, i}=\tan \beta_{i} \cos \eta_{i} \\
& \sin \theta_{\mathrm{m}, i}=\sin \beta_{i} \sin \eta_{i}
\end{aligned}
$$

Besides,

$$
\begin{aligned}
\beta_{\mathrm{n}, i} & =\gamma_{\mathrm{ne}, i}+\theta_{\mathrm{n}, i} \\
\gamma_{\mathrm{ne}, i} & =\tan ^{-1}\left(\tan \gamma_{\mathrm{o}, i} \cos \eta_{i}\right) \\
\theta_{\mathrm{n}, i} & =\tan ^{-1}\left(\frac{d F_{\mathrm{An}, i}}{d F_{\mathrm{Tn}, i}}\right)
\end{aligned}
$$


TABLE 1: Geometric parameters of $\Phi 17.75 \mathrm{~mm}$ staggered teeth BTA drill.

\begin{tabular}{|c|c|c|c|c|c|c|c|c|c|c|}
\hline \multicolumn{3}{|c|}{ Central tooth } & \multicolumn{3}{|c|}{ Intermediate tooth } & \multicolumn{3}{|c|}{ External tooth } & \multirow{2}{*}{$\begin{array}{l}\text { 1st guide pad } \\
\qquad \delta_{1}\end{array}$} & \multirow{2}{*}{$\begin{array}{l}\text { 2nd guide pad } \\
\qquad \delta_{2}\end{array}$} \\
\hline$\gamma_{0,1}$ & $K_{\mathrm{r}, 1}$ & $\lambda_{s, 1}$ & $\gamma_{0,2}$ & $K_{\mathrm{r}, 2}$ & $\lambda_{\mathrm{s}, 2}$ & $\gamma_{0,3}$ & $K_{\mathrm{r}, 3}$ & $\lambda_{\mathrm{s}, 3}$ & & \\
\hline$-5^{\circ}$ & $-15^{\circ}$ & $5^{\circ}$ & $0^{\circ}$ & $18^{\circ}$ & 0 & $0^{\circ}$ & $18^{\circ}$ & $0^{\circ}$ & $87^{\circ}$ & $183^{\circ}$ \\
\hline
\end{tabular}

According to the principle of maximum shear stress, the angle between $d F_{\mathrm{S}, i}$ and $d F_{\mathrm{C}, i}$ is $\pi / 4$. The shear stress in the orthogonal plane of the shear plane is zero [25], and the following equations can be obtained:

$$
\begin{gathered}
F_{\mathrm{S}, i}=F_{\mathrm{C}, i}\left(\cos \theta_{\mathrm{m}, i} \cos \left(\theta_{\mathrm{n}, i}+\phi_{\mathrm{n}, i}\right) \cos \phi_{\mathrm{m}, i}\right. \\
\left.+\sin \theta_{\mathrm{m}, i} \sin \phi_{\mathrm{m}, i}\right)=F_{\mathrm{C}, i} \cos \frac{\pi}{4} \\
F_{\mathrm{C}, i}\left(\cos \theta_{\mathrm{m}, i} \cos \left(\theta_{\mathrm{n}, i}+\phi_{\mathrm{n}, i}\right) \sin \phi_{\mathrm{m}, i}\right. \\
\left.-\sin \theta_{\mathrm{m}, i} \cos \phi_{\mathrm{m}, i}\right)=0
\end{gathered}
$$

Derived by (29) and (30),

$$
\begin{aligned}
\sin \phi_{\mathrm{m}, i} & =\sqrt{2} \sin \theta_{\mathrm{m}, i} \\
\cos \left(\phi_{\mathrm{n}, i}+\theta_{\mathrm{n}, i}\right) & =\frac{\tan \theta_{\mathrm{m}, i}}{\tan \phi_{\mathrm{m}, i}}
\end{aligned}
$$

where chip flow angle $\eta_{i}$ is approximately equal to edge inclination angle $\lambda_{\mathrm{s}, i}$ by using the Stabler chip flow rule.

From (24) (28), (31), and (32), we can calculate $\beta_{\mathrm{n}, i}$, $\beta_{i}, \phi_{\mathrm{n}, i}, \phi_{\mathrm{m}, i}, \theta_{\mathrm{n}, i}$, and $\theta_{\mathrm{m}, i}$. Based on the above-obtained parameters, the shear stress can be calculated by the following equation:

$$
\tau_{\mathrm{s}}=\frac{d F_{\mathrm{s}, i}}{d A_{\mathrm{s}, i}}
$$

where

$$
\begin{aligned}
d F_{\mathrm{s}, i} & =d F_{\mathrm{An}, i} \\
\cdot & \frac{\left(\cos \left(\theta_{\mathrm{n}, i}+\phi_{\mathrm{n}, i}\right) \cos \theta_{\mathrm{m}, \mathrm{i}} \cos \phi_{\mathrm{m}, i}+\sin \theta_{\mathrm{m}, i} \sin \phi_{\mathrm{m}, i}\right)}{\sin \theta_{\mathrm{n}, i} \cos \theta_{\mathrm{m}, i}} \\
d A_{\mathrm{s}, i} & =\frac{t_{\mathrm{c} 0, i} d w}{\cos \lambda_{\mathrm{s}, i} \sin \phi_{\mathrm{n}, i}}=\frac{f d r}{\cos \lambda_{\mathrm{s}, i} \sin \phi_{\mathrm{n}, i}}
\end{aligned}
$$

3.3. Parameters Identification Procedure. To identify the parameters in the model, first, the thrust and torque during the drill entrance are obtained by experiment from a dynamometer. Then, three force components along the cutting radius on the tooth are extracted as described in Section 3.1.
Next, three force components distributed along the cutting radius of on the cutting edge are obtained by adopting the inverse transformation of (7):

$$
\begin{aligned}
& {\left[\begin{array}{lll}
d F_{\mathrm{T}, i} & d F_{\mathrm{R}, i} & d F_{\mathrm{A}, i}
\end{array}\right]^{\mathrm{T}}}
\end{aligned}
$$

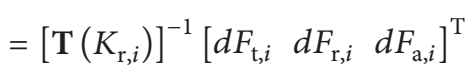

According to the geometric relation of Figure 2, the projection of three force components of the cutting edge unit on the normal plane is

$$
\begin{aligned}
& {\left[\begin{array}{lll}
d F_{\mathrm{Tn}, i} & d F_{\mathrm{Rn}, i} & d F_{\mathrm{An}, i}
\end{array}\right]^{\mathrm{T}}} \\
& \quad=\mathbf{T}\left(\lambda_{\mathrm{s}, i}\right)\left[\begin{array}{lll}
d F_{\mathrm{T}, i} & d F_{\mathrm{R}, i} & d F_{\mathrm{A}, i}
\end{array}\right]^{\mathrm{T}}
\end{aligned}
$$

Then, the force components obtained above are brought into Section 3.2, and $\beta_{\mathrm{n}}, \phi_{\mathrm{n}}, \tau_{s}, \eta_{i}$, and $\gamma_{\mathrm{ne}, i}$ are calculated by means of the constraint relations between the cutting force components and the cutting angles.

Finally, the relevant parameters are taken into the model to calculate the total cutting force and the normal force acting on the guide pads. It is combined with (15) and (16), and we can calculate $\mu_{\mathrm{t}}$ and $\mu_{\mathrm{c}}$.

\section{Experiment and Discussion}

4.1. Experimental Equipment and Methods. The deep hole drilling system used in the experiment is a lathe modified workpiece rotary chip inner removal BTA deep hole drilling machine as shown in Figure 8. The correlative parameters are as follows: the maximum depth of drilling hole is $1000 \mathrm{~mm}$, the drilling tube length is $1200 \mathrm{~mm}$, and the workpiece rotation can be adjusted within the range of $10 \sim 1400$ $\mathrm{r} / \mathrm{min}$. The kinetic viscosity of the cutting oil is $1.33 \times 10$ $2 \mathrm{~Pa} \cdot \mathrm{s}$, the supply pressure is $2.5 \mathrm{MPa}$, and the flow rate is $60 \mathrm{~L} / \mathrm{min}$. The instruments of the drilling force measuring system include the dynamometer, charge amplifier, data acquisition card, and computer. The dynamometer is a thrust and torque sensor (type Kistler 9271A), which is fixed on the end of drilling tube. The charge amplifier amplifies charge signal from the sensor and converts it into a voltage signal. The data acquisition card collects the voltage signal from the charge amplifier and transmits it to the computer for processing, and sampling frequency is $2000 \mathrm{~Hz}$. The workpiece material is alloy steel 18MND5 commonly used in pressure vessels, its length is $300 \mathrm{~mm}$, and the diameter is $100 \mathrm{~mm}$. The drill is a $\Phi 17.75 \mathrm{~mm}$ staggered teeth BTA drill, and its geometric parameters are shown in Table 1. 


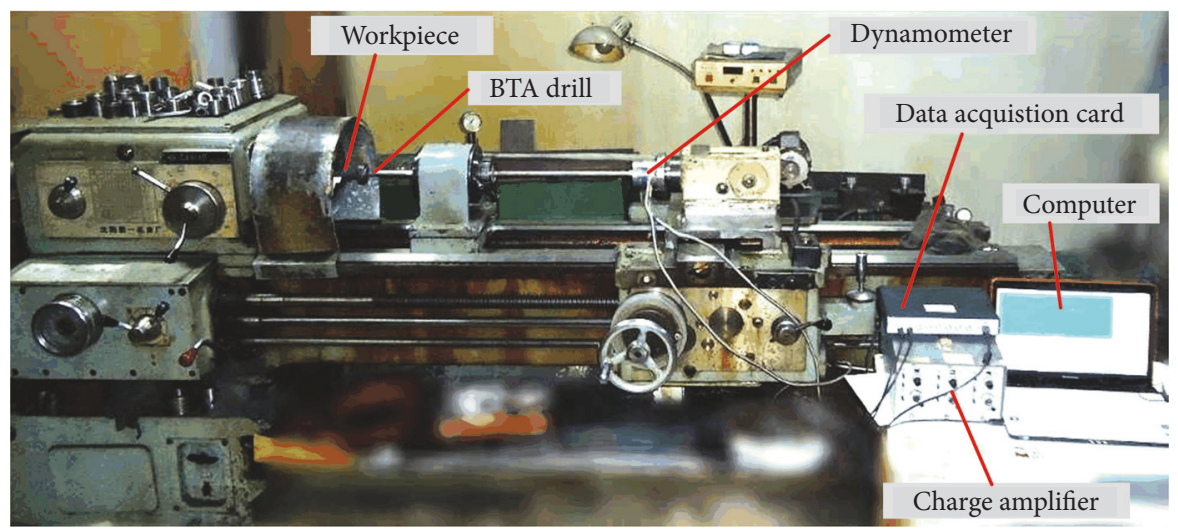

FIGURE 8: Experimental equipment and measuring force system.

TABLE 2: Experimental drilling process parameters.

\begin{tabular}{lcccccc}
\hline Test No. & 1 & 2 & 3 & 4 & 5 & 6 \\
\hline Speed $\mathrm{S} /(\mathrm{r} / \mathrm{min})$ & 540 & 900 & 540 & 900 & 540 & 900 \\
Feed $\mathrm{f} /(\mathrm{mm} / \mathrm{r})$ & 0.0308 & 0.0308 & 0.0495 & 0.0495 & 0.0705 & 0.0705 \\
\hline
\end{tabular}

The selection of the drilling process parameters is shown in Table 2.

4.2. The Distribution of Cutting Force Coefficients. The chip flow angle $\eta_{i}$ and the normal working rake angle $\gamma_{\mathrm{ne}, i}$ are directly determined by the drill geometry parameters. In addition, the normal friction angle $\beta_{\mathrm{n}, i}$, normal shear angle $\phi_{\mathrm{n}, i}$ and shear stress $\tau_{\mathrm{s}}$ along the cutting radius are obtained by using the model parameters identification method in Section 3 and combined with the filtered thrust and torque from tests 1 and 6. The results are shown in Figure 9. The distribution laws of two sets of test results are basically the same. As the cutting radius increases, the normal friction angle decreases, while the normal shear angle increases, and their rate of change decreases. The studies in $[15,26]$ show that, with the increase of cutting radius, the chip thickness deformation coefficient increases and the shear angle increases, which is consistent with the rule of normal shear angle obtained in this paper. According to the distribution of $\beta_{\mathrm{n}}$ and $\phi_{\mathrm{n}}$ with the cutting radius, the double exponential function is used to fit the results of tests 1 and 6 . The fitting results are shown in (38) and (39), where fitness R-square is, respectively, 0.9157 and 0.9041 . The distribution of $\tau_{s}$ with the cutting radius is similar to a horizontal line, which is regarded as a constant value, and its mean value is $774.6 \mathrm{MPa}$.

$$
\begin{aligned}
& \beta_{\mathrm{n}}=-0.9866 \mathrm{e}^{-0.5248 r}+1.208 \mathrm{e}^{-4821 r}+0.458 \\
& \phi_{\mathrm{n}}=-0.2639 \mathrm{e}^{-0.3366 r}+0.01894 \mathrm{e}^{-0.3365 r}+0.4794
\end{aligned}
$$

$\beta_{\mathrm{n}}(r), \phi_{\mathrm{n}}(r)$, and $\tau_{\mathrm{s}}$ and the geometric parameters of the teeth are introduced into (2) to obtain the cutting force coefficients, which are compared with the cutting force model proposed by Woon et al. [11] and the cutting force coefficients obtained in test 3 . The results are shown in Figure 10. In this paper, it is noted that the cutting force coefficients of the model are in good agreement with the actual distribution of the teeth with the cutting radius. The distribution of the three component cutting force coefficients with the cutting radius is basically the same. The smaller the cutting radius, the larger the cutting force coefficients and the greater the change rate. However, in order to increase the chip deformation to benefit chip breaking, the rake angle of the central tooth is designed to be negative and, compared with intermediate tooth and external tooth, the cutting force coefficients of the central tooth are larger, which leads to the discontinuity of the variation curve. Compared with the tangential cutting force coefficients, the axial cutting force coefficients are more affected by the radius, because the smaller the cutting radius, the more serious the indentation of the cutting zone.

The axial friction coefficient $\mu_{\mathrm{t}}$ is 0.0964 and the circumferential friction coefficient $\mu_{c}$ is 0.398 between the guide pads and the hole wall. However, in [27], the circumferential friction coefficient of the guide pads is 0.676 , obtained from the friction and wear experiment. Since the experimental condition is dry friction and the whole guide pad is in contact with the workpiece, the drill is in the cutting oil during the actual BTA deep hole drilling. The guide pad is designed with a wedge-shaped angle, and the actual contact area with the hole wall is very small. At the top of the guide pad at $1 \sim 2 \mathrm{~mm}$, a dynamic oil film will be formed on the circumferential surface of the non-high-pressure contact area of the guide pad [21], thus reducing friction. The equivalent friction coefficient of the guide pad obtained in this paper is more closely related to the actual situation.

4.3. Model Verification and Analysis. To verify the accuracy of the model, three sets of test parameters are selected from Table 2 to study the thrust and torque during the drill entrance and drilling. The experimental results and model prediction results under different drilling process 
TABLE 3: Comparison of predicted values with experimental values of cutting and burnishing force.

\begin{tabular}{|c|c|c|c|c|c|c|c|c|c|c|c|c|}
\hline \multirow{3}{*}{ Test No. } & \multicolumn{6}{|c|}{ Teeth cutting force } & \multicolumn{6}{|c|}{ Guide pads burnishing force } \\
\hline & \multicolumn{3}{|c|}{$F_{\mathrm{ZC}} / \mathrm{N}$} & \multicolumn{3}{|c|}{$M_{\mathrm{ZC}} /(\mathrm{N} \cdot \mathrm{m})$} & \multicolumn{3}{|c|}{$F_{\mathrm{ZB}} / \mathrm{N}$} & \multicolumn{3}{|c|}{$M_{\mathrm{ZB}} /(\mathrm{N} \cdot \mathrm{m})$} \\
\hline & Pred & Exp & Error $(\%)$ & Pred & Exp & Error $(\%)$ & Pred & Exp & Error $(\%)$ & Pred & Exp & Error $(\%)$ \\
\hline 2 & 500.9 & 525.8 & -4.74 & 3.335 & 3.174 & 5.07 & 43.62 & 48.37 & -9.82 & 1.598 & 1.491 & 7.18 \\
\hline 4 & 805.2 & 834.7 & -3.53 & 5.359 & 5.711 & -6.16 & 70.25 & 67.45 & 4.15 & 2.569 & 2.317 & 10.8 \\
\hline 5 & 1147.2 & 1043.6 & 9.93 & 7.633 & 7.296 & 4.62 & 99.34 & 106.60 & -6.81 & 3.657 & 3.714 & -1.53 \\
\hline
\end{tabular}

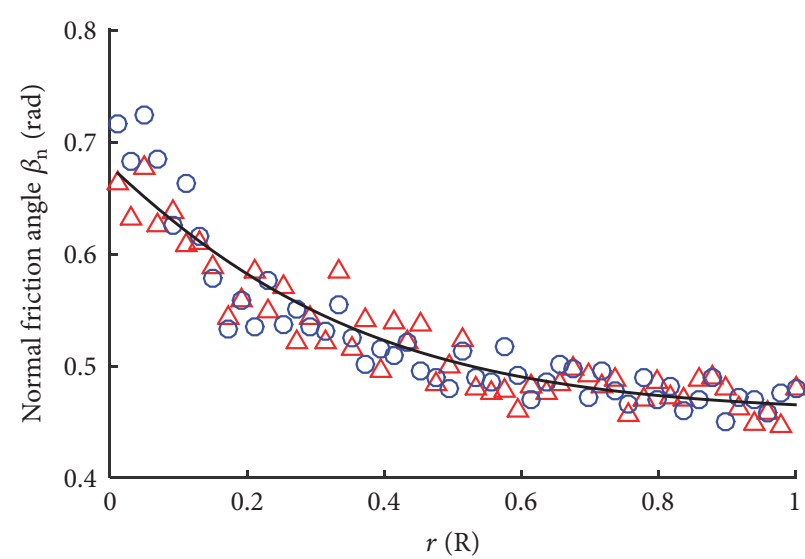

$\begin{array}{cc}\triangle & \text { Test } 1 \text { result } \\ \bigcirc & \text { Test } 6 \text { result } \\ & \text { Fitted curve }\end{array}$

(a) Distribution of $\beta_{n}$ with cutting radius

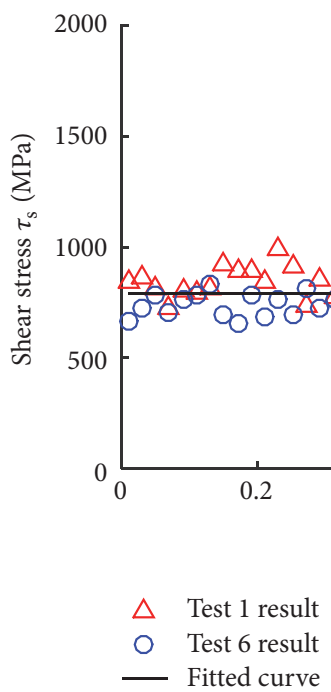

(c) Distribution of $\tau_{\mathrm{s}}$ with cutting radius

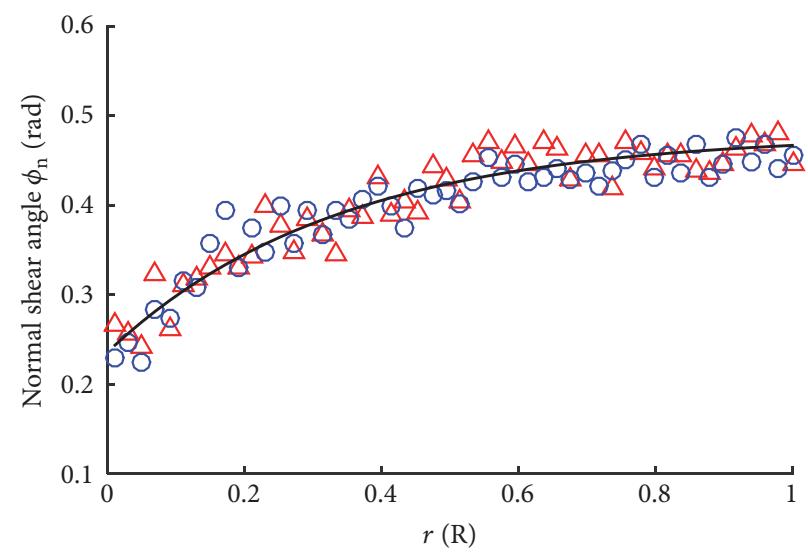

$\begin{array}{cc}\triangle & \text { Test } 1 \text { result } \\ \bigcirc & \text { Test } 6 \text { result } \\ & \text { Fitted curve }\end{array}$

(b) Distribution of $\phi_{\mathrm{n}}$ with cutting radius

FIGURE 9: Distribution of cutting parameters of the tooth.

parameters are shown in Figure 11. With the increase of drilling time, the teeth and guide pads enter the workpiece in turn, the thrust and torque of drilling increase, and the drilling force is at a stable stage when the guide pads enter the workpiece completely. The model prediction results are in good agreement with the experiments. The experimental and predicted cutting force of the teeth and the burnished friction force of guide pads under different drilling conditions are shown in Table 3. The thrust and torque produced by the burnished friction of guide pads, respectively, account 


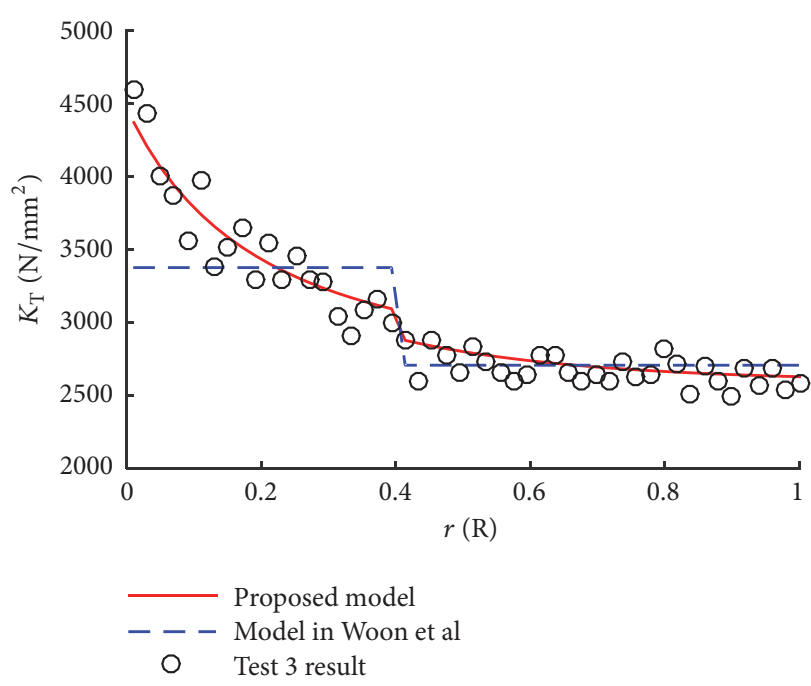

(a) Distribution of $K_{\mathrm{T}}$ with cutting radius

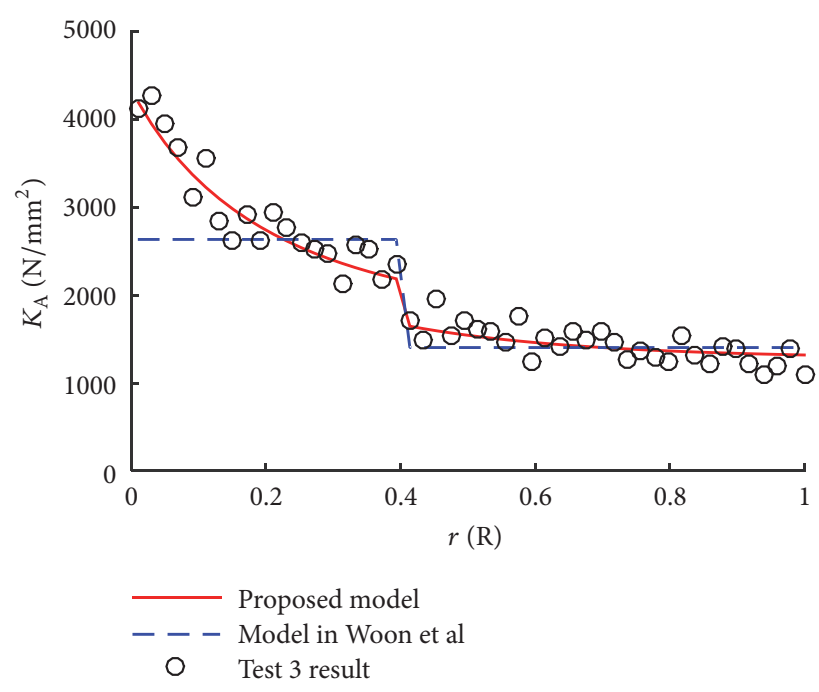

(c) Distribution of $K_{\mathrm{A}}$ with cutting radius

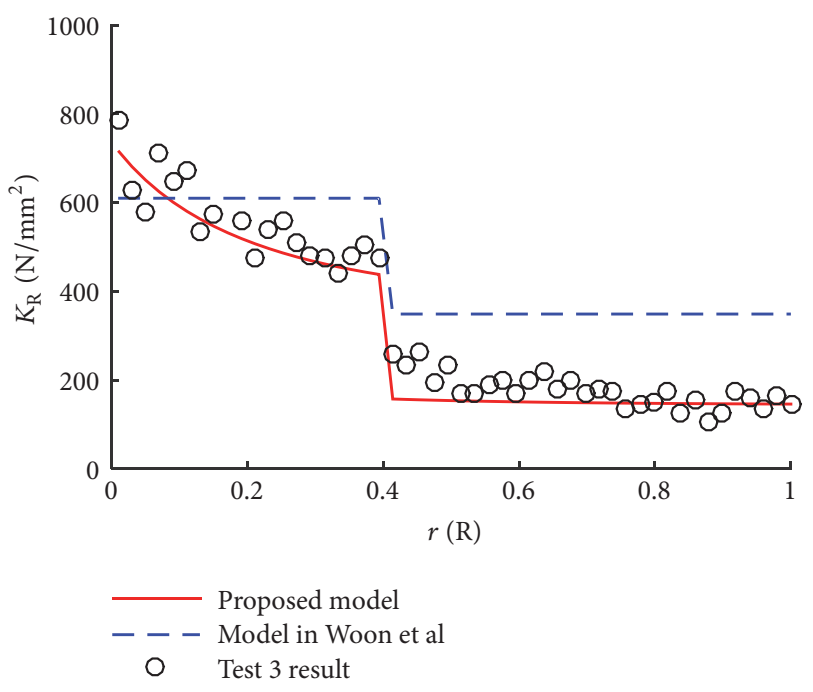

(b) Distribution of $K_{\mathrm{R}}$ with cutting radius

FIGURE 10: Distribution of cutting force coefficients with cutting radius.

for $8.37 \%$ and $31.52 \%$ of the total force. The average errors of thrust and torque produced by cutting of the teeth are $6.07 \%$ and $5.28 \%$, respectively, and the average errors of thrust and torque produced by burnishing of the guide pads are $6.93 \%$ and $6.50 \%$, respectively. The results show that the model can accurately predict the distribution of cutting force with the cutting radius and burnished friction force of guide pads.

The possible reason for the error of the drilling force model is that the stiffness of the BTA deep hole drilling tool system is poor, and the fluctuation of drilling force causes the axial vibration of the drilling tube and changes the uncut layer thickness. In addition, the influence of drilling parameters on the dynamic characteristics of the deep hole drilling system is not taken into account in the modeling process. The fluctuation of drilling radial force and tangential force will cause the chatter of the tool system and lead to the change of the cutting width of the tooth. Moreover, the drilling process parameters will also affect the state of chip deformation and breaking, resulting in poor chip removal and cutting oil pressure fluctuation.

\section{Conclusions}

In this paper, a novel drilling force model was developed to predict the thrust and torque for staggered teeth BTA deep hole drill with variable geometries, based on the oblique cutting theory, and a method of identifying the relevant parameters in the model through drilling force during the drill entrance was proposed, which was verified by experiments. From the above study, the following conclusions are drawn. 


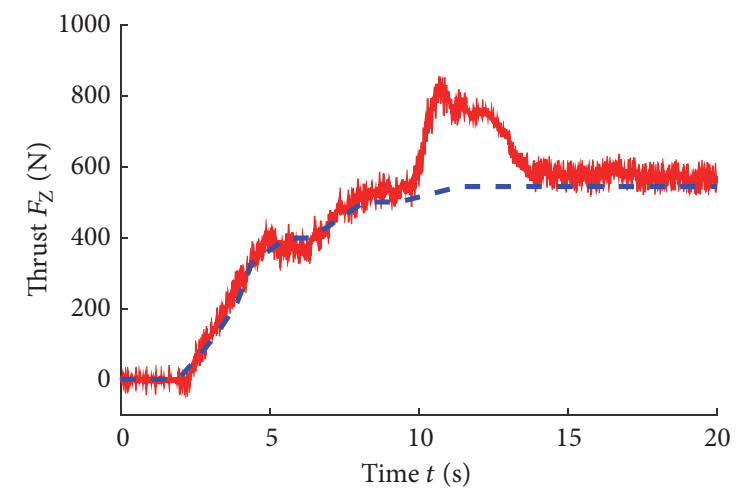

- - - Predicted result

Test 2 result

(a) Thrust of test 2 and predicted

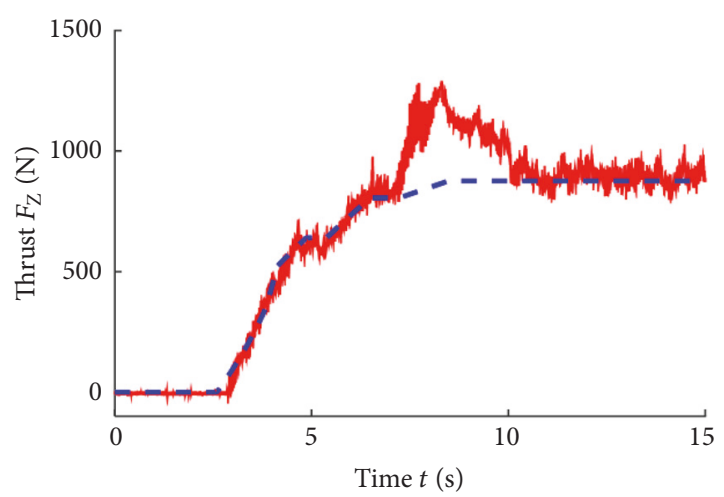

- - - Predicted result

Test 4 result

(c) Thrust of test 4 and predicted

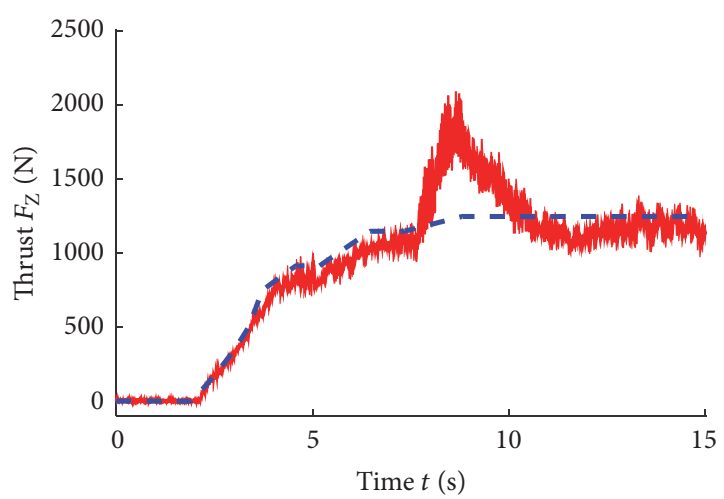

$-\ldots$ Predicted result
- Test 5 result

(e) Thrust of test 5 and predicted

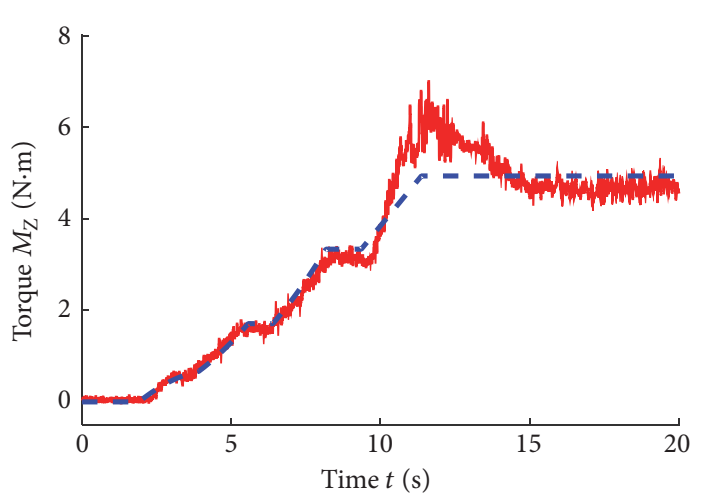

- - - Predicted result

Test 2 result

(b) Torque of test 2 and predicted

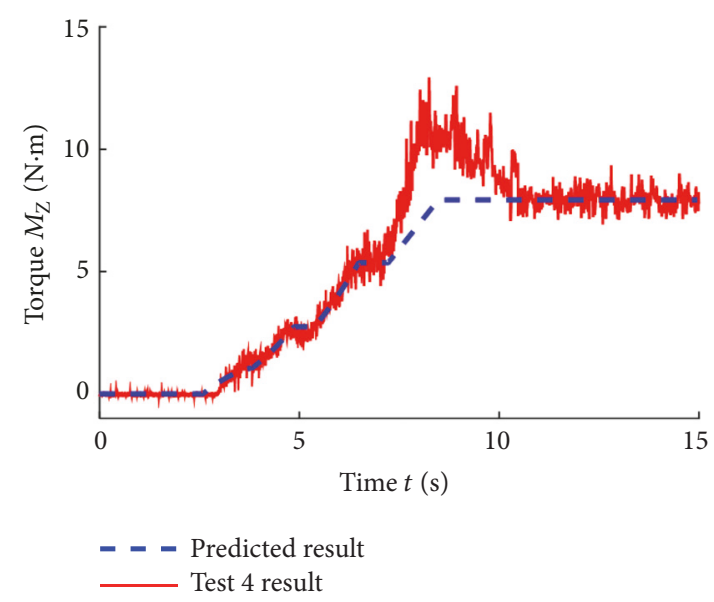

(d) Torque of test 4 and predicted

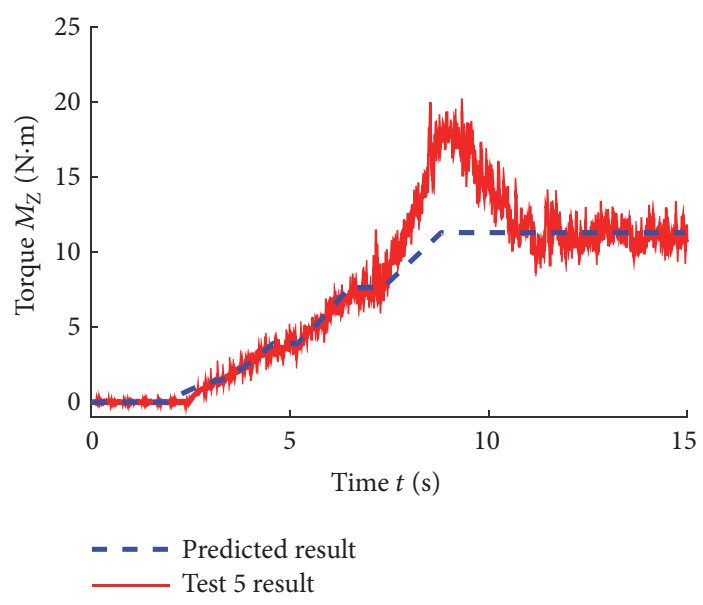

(f) Torque of test 5 and predicted

FIGURE 11: Comparison of predicted and experimental results in the drilling process.

The normal shear angle and normal friction angle are distributed as a double exponential function along the cutting radius. The shear stress is constant, and the axial and circumferential friction coefficients between the guide pad and the hole wall are 0.0964 and 0.398 , respectively.
The cutting radius has a great influence on the cutting force coefficients, and the smaller the cutting radius, the greater the cutting force coefficients. The thrust and torque generated by the burnished friction of the guide pads account for $8.37 \%$ and $31.52 \%$ of the total force, respectively. 
The model prediction results correspond well with the experimental results. The model can accurately predict the distribution of the cutting force with the cutting radius and the burnished friction force of guide pads.

\section{Data Availability}

The data used to support the findings of this study are available from the corresponding author upon request.

\section{Conflicts of Interest}

The authors declare that they have no conflicts of interest.

\section{Acknowledgments}

This work was supported by National Science and Technology Major Project of China (Grant no. 2013ZX04009011), National Natural Science Foundation of China (Grant no. 51475367), Key Laboratory Project of Shaanxi Education Department (Grant no. 17JS093), and Natural Science Foundation of Department of Education of Shaanxi Province (Grant no. 2018JM5113).

\section{References}

[1] G. L. Tnay, S. Wan, K. S. Woon, and S. H. Yeo, "The effects of dub-off angle on chip evacuation in single-lip deep hole gun drilling," The International Journal of Machine Tools and Manufacture, vol. 108, pp. 66-73, 2016.

[2] K. Matsuzaki, T. Ryu, A. Sueoka, and K. Tsukamoto, “Theoretical and experimental study on rifling mark generating phenomena in BTA deep hole drilling process (generating mechanism and countermeasure)," The International Journal of Machine Tools and Manufacture, vol. 88, pp. 194-205, 2015.

[3] R. Richardson and R. Bhatti, "Review of research into the role of guide pads in BTA deep-hole machining," Journal of Materials Processing Technology, vol. 110, no. 1, pp. 61-69, 2001.

[4] C.-S. Deng, J.-C. Huang, and J.-H. Chin, "Effects of support misalignments in deep-hole drill shafts on hole straightness," The International Journal of Machine Tools and Manufacture, vol. 41, no. 8, pp. 1165-1188, 2001.

[5] X. Zhang, G. L. Tnay, K. Liu, and A. S. Kumar, "Effect of apex offset inconsistency on hole straightness deviation in deep hole gun drilling of Inconel 718," The International Journal of Machine Tools and Manufacture, vol. 125, pp. 123-132, 2018.

[6] A. Chaudhari, S. Malarvizhi, K. S. Woon, A. Senthil Kumar, and M. Rahman, "The effects of pilot hole geometry on toolwork engagement efficacy in deep hole drilling," Journal of Manufacturing Processes, vol. 19, pp. 135-141, 2015.

[7] L. Kong, J.-H. Chin, Y. Li, Y. Lu, and P. Li, "Targeted suppression of vibration in deep hole drilling using magneto-rheological fluid damper," Journal of Materials Processing Technology, vol. 214, no. 11, pp. 2617-2626, 2014.

[8] M. A. W. Hussien, B. B. Rama, and D. Kudret, "Whirling vibrations in boring trepanning association deep hole boring process: analytical and experimental investigations," Journal of Manufacturing Science and Engineering, vol. 129, no. 1, pp. 4862, 2007.
[9] J. Jung and F. Ke, "A gundrilling force system," The International Journal of Machine Tools and Manufacture, vol. 47, no. 7-8, pp. 1276-1284, 2007.

[10] S. K. Sahu, R. E. Devor, and S. G. Kapoor, "Modeling of forces for drills with chip-breaking grooves," Journal of Manufacturing Science and Engineering, vol. 126, no. 3, pp. 555-564, 2004.

[11] K. S. Woon, A. Chaudhari, M. Rahman, S. Wan, and A. S. Kumar, "The effects of tool edge radius on drill deflection and hole misalignment in deep hole gundrilling of Inconel-718," CIRP Annals - Manufacturing Technology, vol. 63, no. 1, pp. 125128, 2014.

[12] D. Biermann, M. Kersting, and N. Kessler, "Process adapted structure optimization of deep hole drilling tools," CIRP Annals - Manufacturing Technology, vol. 58, no. 1, pp. 89-92, 2009.

[13] M.-B. Lazar and P. Xirouchakis, "Mechanical load distribution along the main cutting edges in drilling," Journal of Materials Processing Technology, vol. 213, no. 2, pp. 245-260, 2013.

[14] A. R. Watson, "Drilling model for cutting lip and chisel edge and comparison of experimental and predicted results. II-revised cutting lip model," International Journal of Machine Tool Design and Research, vol. 25, no. 4, pp. 367-376, 1985.

[15] C. H. Gao, K. Cheng, and D. Kirkwood, "Investigation on the machining process of BTA deep hole drilling," Journal of Materials Processing Technology, vol. 107, no. 1-3, pp. 222-227, 2000.

[16] V. P. Astakhov and M. O. M. Osman, "An analytical evaluation of the cutting forces in self-piloting drilling using the model of shear zone with parallel boundaries. Part 1: Theory," The International Journal of Machine Tools and Manufacture, vol. 36, no. 11, pp. 1187-1200, 1996.

[17] V. P. Astakhov and M. O. M. Osman, "An analytical evaluation of the cutting forces in self-piloting drilling using the model of shear zone with parallel boundaries. Part 2: Application," The International Journal of Machine Tools and Manufacture, vol. 36, no. 12, pp. 1335-1345, 1996.

[18] F. Ke, J. Ni, and D. A. Stephenson, "Chip thickening in deephole drilling," The International Journal of Machine Tools and Manufacture, vol. 46, no. 12-13, pp. 1500-1507, 2006.

[19] B. J. Griffiths, "Modelling complex force systems, part 1: The cutting and pad forces in deep drilling," Journal of Manufacturing Science and Engineering, vol. 115, no. 2, pp. 169-176, 1993.

[20] K. Sakuma, K. Taguchi, and A. Katsuki, "Study on Deep-holedrilling with Solid-boring Tool : The Burnishing Action of Guide Pads and Their Influence on Hole Accuracies," Journal of the Japan Society of Mechanical Engineers, vol. 23, no. 185, pp. 1921-1928, 1980.

[21] K. Sakuma, K. Taguchi, A. Katsuki, and H. Takeyama, "SelfGuiding Action of Deep-Hole-Drilling Tools," CIRP Annals Manufacturing Technology, vol. 30, no. 1, pp. 311-315, 1981.

[22] H. Zhang, X. Shen, A. Bo, Y. Li, H. Zhan, and Y. Gu, "A multiscale evaluation of the surface integrity in boring trepanning association deep hole drilling," The International Journal of Machine Tools and Manufacture, vol. 123, pp. 48-56, 2017.

[23] E. J. A. Armarego and R. C. Whitfield, "Computer Based Modelling of Popular Machining Operations for Force and Power Prediction," CIRP Annals - Manufacturing Technology, vol. 34, no. 1, pp. 65-69, 1985.

[24] Y. Altintas and Z. M. Kilic, "Generalized dynamic model of metal cutting operations," CIRP Annals - Manufacturing Technology, vol. 62, no. 1, pp. 47-50, 2013. 
[25] E. Shamoto and Y. Altintas, "Prediction of shear angle in oblique cutting with maximum shear stress and minimum energy principles," Journal of Manufacturing Science and Engineering, vol. 121, no. 3, pp. 399-407, 1999.

[26] J. Thil, B. Haddag, M. Nouari, C. Barlier, and L. Papillon, "Experimental and analytical analyses of the cutting process in the deep hole drilling with BTA (boring trepanning association) system," Mechanics \& Industry, vol. 14, no. 6, pp. 413-429, 2013.

[27] J. Truhan, R. Menon, F. LeClaire, J. Wallin, J. Qu, and P. Blau, "The friction and wear of various hard-face claddings for deephole drilling," Wear, vol. 263, no. 1-6, pp. 234-239, 2007. 


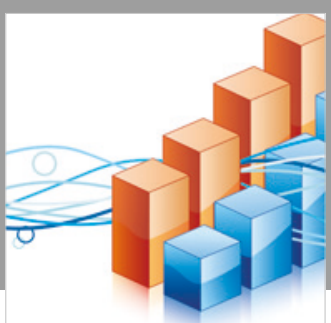

Advances in

Operations Research

\section{-n-m}
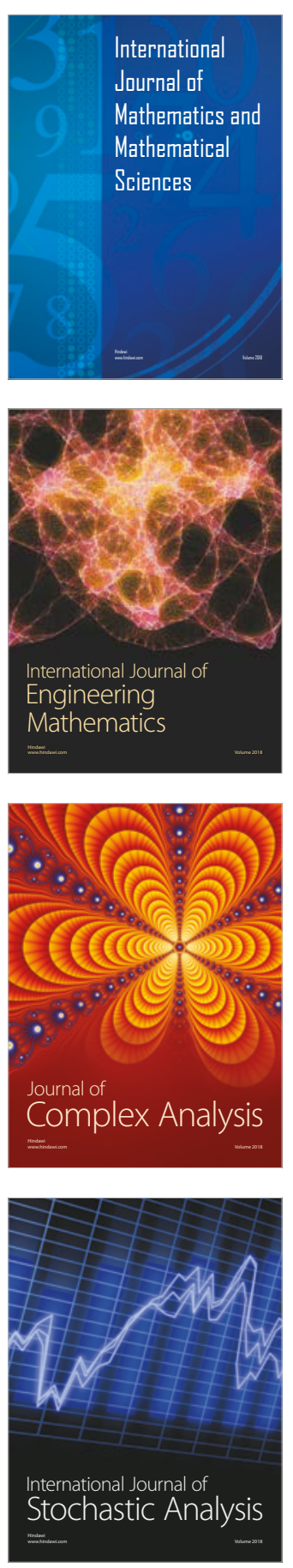
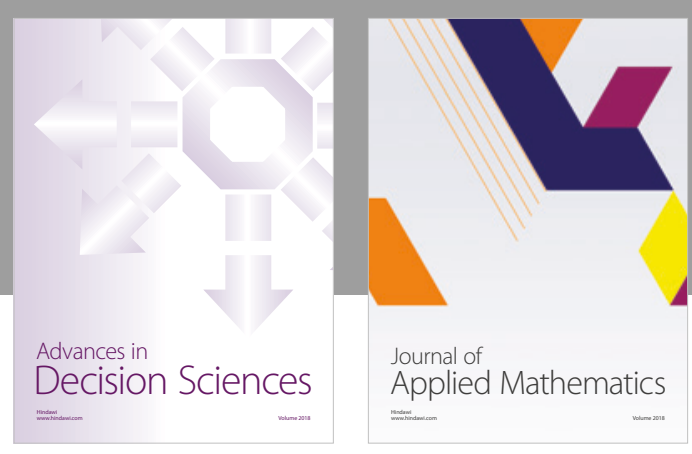

Journal of

Applied Mathematics
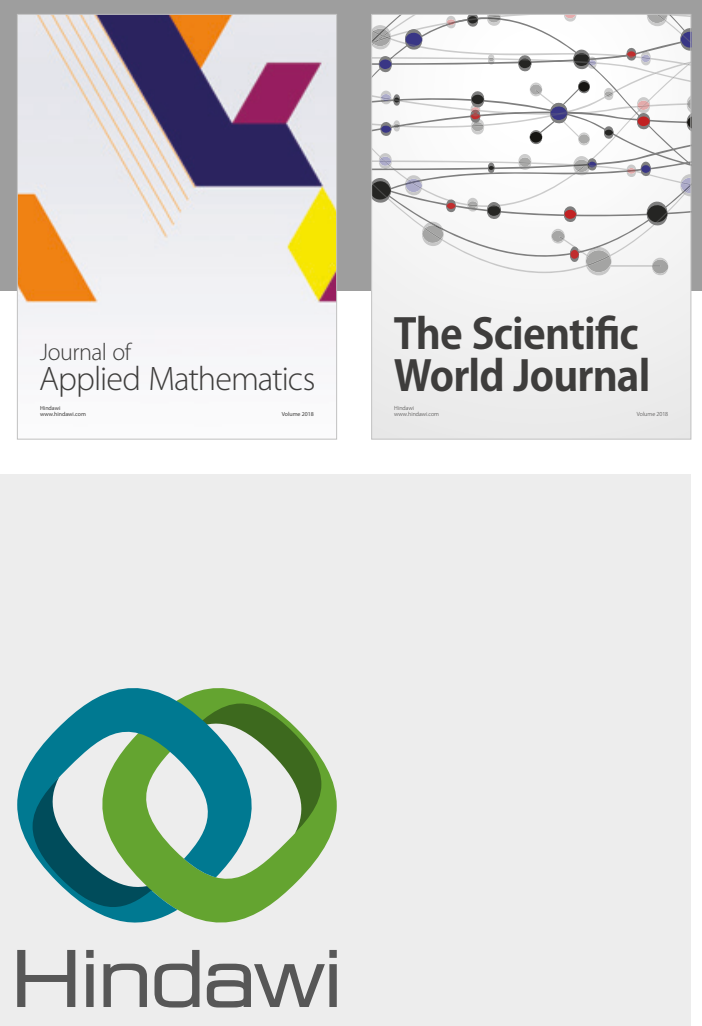

Submit your manuscripts at

www.hindawi.com

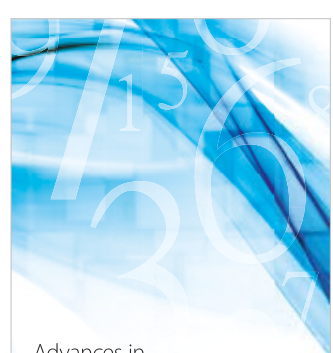

Advances in
Numerical Analysis
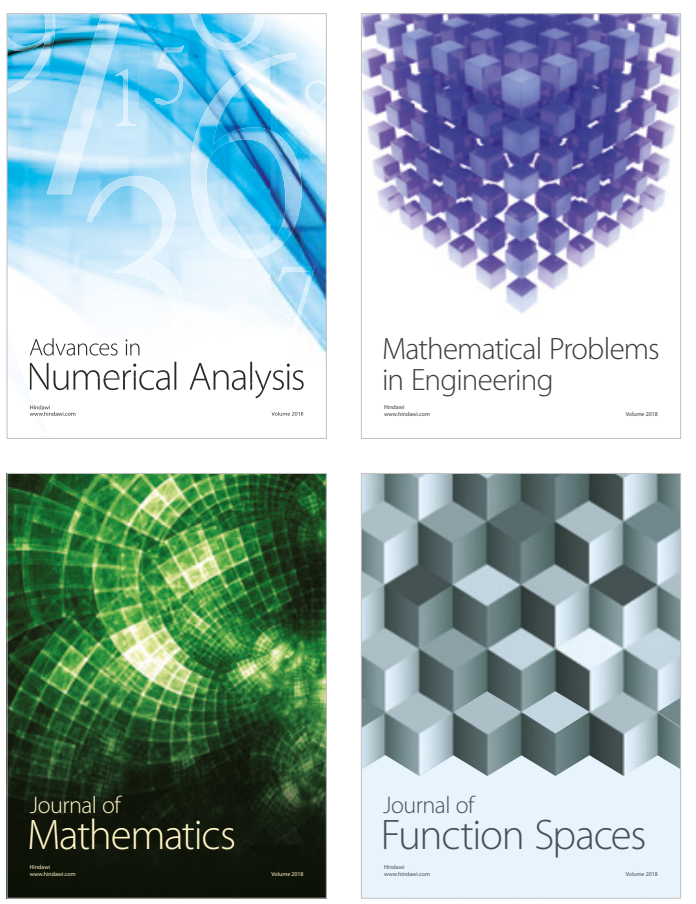

Mathematical Problems in Engineering

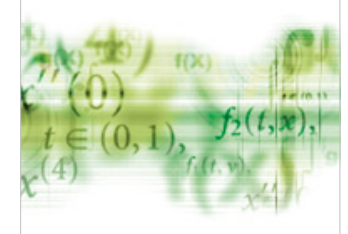

International Journal of

Differential Equations

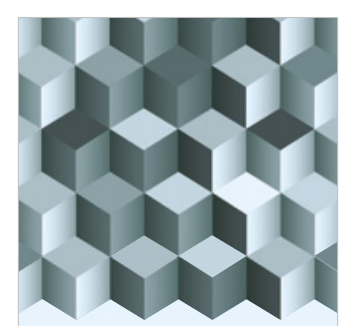

Journal of

Function Spaces

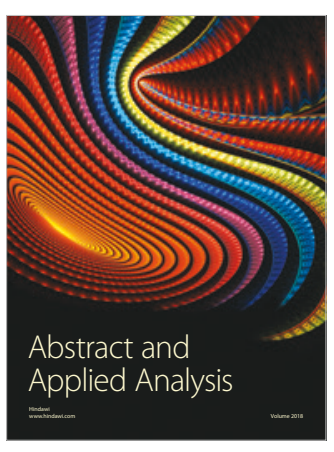

The Scientific

World Journal

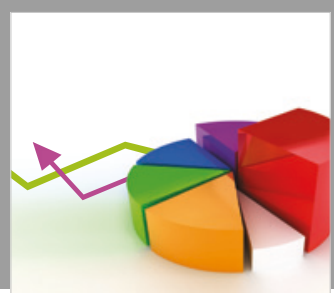

Journal of

Probability and Statistics
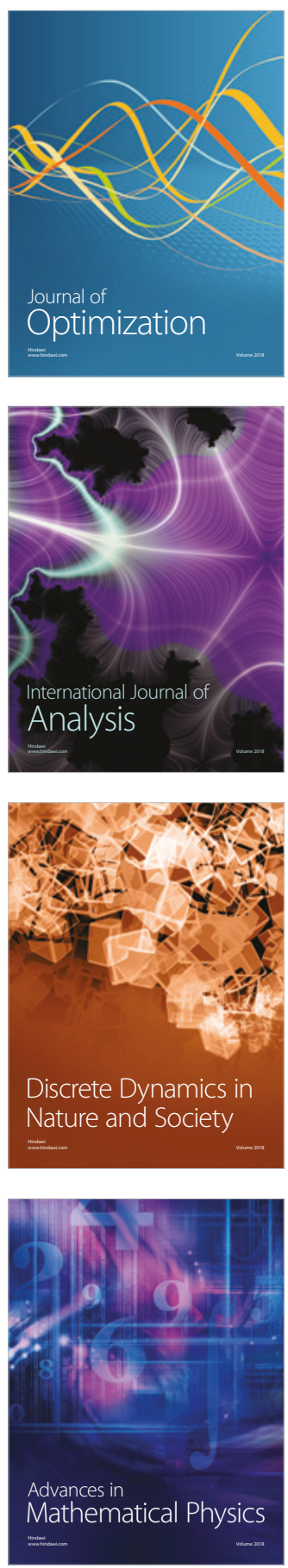